\title{
Understanding the barriers and improving care in type 2 diabetes: Brazilian perspective in time to do more in diabetes
}

\author{
Sérgio Vencio ${ }^{1,7^{*}}$, Päivi M. Paldánius ${ }^{2}$, Matthias Blüher ${ }^{3}$, Daniel Giannella-Neto ${ }^{4 \wedge}$, Rafael Caiado-Vencio ${ }^{5}$ \\ and W. David Strain ${ }^{6}$
}

\begin{abstract}
Background: Type 2 diabetes mellitus (T2DM) is a complex disease, particularly in a continental country like Brazil. We attempted to understand and evaluate the perceptions and routines of Brazilians with T2DM and physicians, compared with other countries.

Methods: We compared the results from a 20-min online survey in Brazil with simultaneously collated data from India, Japan, Spain, UK and USA.

Results: In total, 652 adults with T2DM and 337 treating physicians were enrolled, of whom 100 patients and 55 physicians were from Brazil. The numbers of primary care physicians from the five countries were 221 versus 43 in Brazil, diabetes specialists were 61 versus 12. There was disconnect between the opinions of physicians and people with diabetes globally. Further, there were differences between clinical practices in Brazil versus the rest of the world, in many areas Brazilians were performing better.
\end{abstract}

Conclusions: Communication between patients and physicians should be clearer. There is an urgent need to identify the deficits in education, in order to address the clinical inertia within the diabetes management team. There is a necessity to understand the specific requirements of the Brazilian population in order to contextualise international guidelines and implement local changes in practice.

Keywords: Diabetes, Clinical inertia, Brazil

\section{Background}

According to International Diabetes Federation, approximately 14.3 million people are living with diabetes in Brazil, and this number is expected to increase to 23.3 million by the year 2040 [1]. Good glycaemic control soon after diagnosis, results in significant long-term benefits, reducing the prevalence of micro and macrovascular complications. These benefits persist for many years, indeed the glycaemic control at diagnosis affects outcomes many years later [2]. As diabetes progresses, the

\footnotetext{
*Correspondence: svencio@gmail.com

$\wedge$ Deceased

${ }^{7}$ Avenida T-4 número 313 Setor Bueno, Goiânia, Goiás CEP 74884-582, Brazil

Full list of author information is available at the end of the article
}

benefit of a good glycaemic control is attenuated and may even be paradoxically reversed [3].

Despite this knowledge, however, there remains a substantial gap between clinical aspirations and targets achieved [4]. A significant contributor to this gap is clinical inertia, that is, a delay in escalating therapy at the appropriate time. Clinical inertia has been widely recognised as a barrier in the management of diabetes for many years; however, the proportion of people with diabetes achieving blood pressure, lipid and glycaemic targets has not substantially improved [5]. Recently, the clinical consequences of inertia have also been associated with increased incidence of cardiovascular complications in subjects not achieving their glycaemic targets [6]. This is partially due to a lack of understanding of the factors that influence escalation of therapy. Most of the studies 
have explored the determinants of clinical inertia in USA, UK and few South-Asian countries [7-9], however, studies highlighting factors responsible for clinical inertia in Brazil are lacking even though the rate at which people being affected with diabetes is increasing alarmingly [1]. We conducted a survey (Time to do More) involving both people with diabetes and physicians across six countries in order to understand the potential causes of clinical inertia. The current subanalysis of the 'Time to do More' survey aimed to understand the perceptions and routines of patients with type 2 diabetes and physicians in Brazil in comparison to rest of the countries (USA, UK, Spain, India and Japan).

\section{Methods}

Details of the Time to do More survey have been published elsewhere [10]. Briefly, individuals from the Kantar Health panel of over 2500 physicians and 118,000 patients who agreed to be contacted for research purposes were randomly invited for a 20-min online survey. After introduction of quotas, the survey enrolled 652 people with type 2 diabetes and 337 physicians (264 general practitioners [GPs]; 73 specialists) treating diabetes, from Brazil, Japan, India, Spain, UK and USA. Fifty-five
Brazilian physicians and 100 Brazilian people with diabetes contributed to the final results (Table 1).

The survey was designed with the following objectives:

- To identify barriers in improving the treatment of type 2 diabetes mellitus (T2DM) and understand the ways in which these can be overcome.

- To understand clinical inertia and to what extent it constitutes a barrier to improving care in T2DM.

- To explore perceptions on treating earlier and more aggressively.

- To identify areas of unmet need.

Inclusion criteria are provided in Table 2.

Specific questions explored recollection from both physicians and people with diabetes on topics discussed at initial diagnosis consultation and follow-up consultations, attitudes towards complications, adequate disease management and perceived likelihood of achieving treatment targets. Physicians were also questioned regarding any modification to treatment algorithms for elderly patients (aged 80 years) or those with co-morbidities (as typified by renal impairment) compared to a typical 50-year old individual with diabetes. Responses from

Table 1 Demographic characteristics of the patients and physicians

\begin{tabular}{|c|c|c|c|c|c|c|}
\hline & USA $(n=151)$ & UK $(n=100)$ & Spain $(n=100)$ & India $(n=100)$ & Japan $(n=101)$ & Brazil $(n=100)$ \\
\hline Male & $58 \%$ & $60 \%$ & $60 \%$ & $62 \%$ & $72 \%$ & $60 \%$ \\
\hline Female & $42 \%$ & $40 \%$ & $40 \%$ & $38 \%$ & $28 \%$ & $40 \%$ \\
\hline Mean age (in years) & 60.6 & 59.6 & 53.3 & 52.3 & 57.8 & 52.4 \\
\hline Mean BMI (kg/m²) & 33.1 & 31.0 & 28.9 & 24.7 & 24.9 & 33.9 \\
\hline Employed full-time & $20 \%$ & $26 \%$ & $29 \%$ & $53 \%$ & $47 \%$ & $48 \%$ \\
\hline Employed part-time & $7 \%$ & $18 \%$ & $13 \%$ & $13 \%$ & $7 \%$ & $22 \%$ \\
\hline Student & - & - & - & $1 \%$ & - & $3 \%$ \\
\hline Not working for health reasons & $17 \%$ & $9 \%$ & $7 \%$ & $4 \%$ & $3 \%$ & $8 \%$ \\
\hline Not working for other reasons & $9 \%$ & $1 \%$ & $27 \%$ & $4 \%$ & $13 \%$ & $2 \%$ \\
\hline Retired & $47 \%$ & $46 \%$ & $24 \%$ & $25 \%$ & $31 \%$ & $17 \%$ \\
\hline Low income & $33 \%$ & $46 \%$ & $85 \%$ & $31 \%$ & $52 \%$ & $8 \%$ \\
\hline Middle income & $48 \%$ & $28 \%$ & $3 \%$ & $30 \%$ & $35 \%$ & $23 \%$ \\
\hline High income & $15 \%$ & $10 \%$ & $4 \%$ & $33 \%$ & $5 \%$ & $66 \%$ \\
\hline \multirow[t]{2}{*}{ Prefer not to say } & $4 \%$ & $16 \%$ & $8 \%$ & $6 \%$ & $8 \%$ & $3 \%$ \\
\hline & USA (n = 75) & UK $(n=50)$ & Spain $(n=51)$ & India $(n=50)$ & Japan $(n=56)$ & Brazil (n = 55) \\
\hline PCPs & $80 \%$ & $80 \%$ & $80 \%$ & $80 \%$ & $71 \%$ & $78 \%$ \\
\hline Endocrinologist/diabetologist & $20 \%$ & $20 \%$ & $20 \%$ & $20 \%$ & $29 \%$ & $22 \%$ \\
\hline $\begin{array}{l}\text { Mean time as a medical doctor } \\
\text { (in years) }\end{array}$ & 18 & 19 & 17 & 14 & 24 & 15 \\
\hline $\begin{array}{l}\text { Average proportion of time spent } \\
\text { counselling patients }\end{array}$ & $97 \%$ & $87 \%$ & $88 \%$ & $81 \%$ & $92 \%$ & $91 \%$ \\
\hline $\begin{array}{l}\text { Average number of T2DM } \\
\text { patients seen in a month }\end{array}$ & 170 & 102 & 125 & 261 & 209 & 124 \\
\hline
\end{tabular}

$B M I$ body mass index, $P C P$ s primary care physicians, $T 2 D M$ type 2 diabetes mellitus 
Table 2 Inclusion criteria for physicians and patients

\begin{tabular}{lc}
\hline Physician screening criteria & Patient screening criteria \\
\hline 3-35 years in practice & Confirmed diagnosis of T2DM \\
$\begin{array}{l}\text { Spend at least 70\% of time in patient management } \\
\begin{array}{l}\text { Every month see at least 50 patients with T2DM (for PCPs), 100 patients for } \\
\text { specialists }\end{array}\end{array}$ & $\begin{array}{c}\text { Quotas on age, gender, number of pills taken in a day, economic } \\
\text { background (low, average, high income brackets) }\end{array}$ \\
Prescribes oral and/or injectableT2DM treatments & \\
\hline
\end{tabular}

PCPs primary care physicians, T2DM type 2 diabetes mellitus

Brazil were compared against those pooled from Japan, India, Spain, UK and USA. Continuous data were used whenever possible to maximize power.

\section{Results}

Overall, 100 people with diabetes from Brazil completed the survey, compared to 552 from the rest of the world. There were 43 PCPs from Brazil, compared to 221 in the global pool and 12 diabetes specialists compared with 61 from Japan, India, Spain, UK and USA.

\section{Initial consultation visit: diagnosis}

Globally, $68 \%$ of participants with diabetes received diagnosis from a PCP, however, in Brazil the responsibility was reversed, such that $53 \%$ of participants recall their initial diabetes counselling coming from a specialist, with PCPs accounting for a further $34 \%$ and other specialists, particularly cardiologists and nurses confirming the diagnosis for the rest of the participants.

This involvement with diabetes specialists at diagnosis translated into longer initial consultations, with a quarter of Brazilians being offered $>40 \mathrm{~min}$, and only $17 \%$ receiving $<20 \mathrm{~min}$. This compares very favourably with figures worldwide, where $74 \%$ of initial consultations lasted $<20$ min and a further $19 \%$ of people only receiving between 20 and $40 \mathrm{~min}$.

People with diabetes in Brazil had similar perception about their initial consultation, with $72 \%$ recalling longer than $20 \mathrm{~min}$ and $36 \%$ longer than $30 \mathrm{~min}$. However, globally, only $61 \%$ people with diabetes recalled receiving consultation for at least $20 \mathrm{~min}$.

\section{Topics discussed during initial consultation}

Lifestyle changes, disease and its causes and drug treatment were topics discussed by almost all physicians at the diagnosis consultation; however, fewer patients recalled these topics being discussed (Fig. 1).

There were no important differences across countries in topics that were discussed at the diagnosis consultation or in the recollection of these topics. Lifestyle changes, such as diet and exercise, were discussed by physicians of all countries in nearly all cases, and the importance of

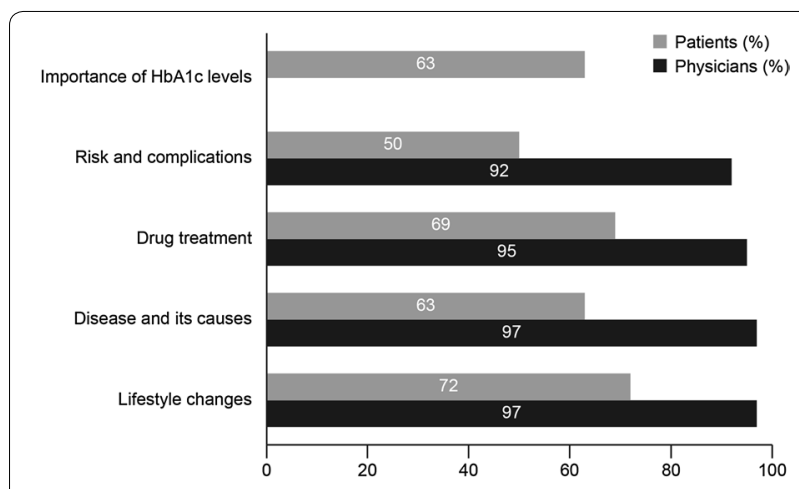

Fig. 1 Respondents (physicians [ $n=337$ ], patients [ $n=652]$ ) recall of the topics discussed at the diagnosis consultation. HbA1C glycosylated haemoglobin

glycaemic targets was discussed in $85 \%$ of consultations in Brazil and $89 \%$ globally.

A vast majority of physicians discussed the disease and its causes, drug treatment and risks and complications of T2DM, whereas about 1 in 5 patients had no recollection of any of these. A similar number of patients recalled discussing lifestyle changes in Brazil (13\%) as in the rest of the world (16\%). The impact of other health conditions on the management of diabetes was discussed only in a small minority of patients globally (2\%); this discussion was twice as likely to be had in Brazil (5\%). However, it is impossible to determine whether it was due to a higher prevalence of co-morbidities at diagnosis in Brazilian people with diabetes compared with the rest of the world. Fewer people from Brazil recalled the discussion about risks and complications of T2DM (6\%) compared with the other countries (9\%).

The longer duration of initial consultation was associated with fewer people with diabetes having difficulty in understanding the topics discussed. Managing the disease during fasting periods was considered difficult to understand for $35 \%$ globally versus $20 \%$ in Brazil. Similarly, less than half of people with diabetes in Brazil struggled to understand the costs associated with treating diabetes compared with the rest of the world $(10 \%$ vs $25 \%$ respectively), and the potential side effects of this 
treatment caused fewer concerns amongst Brazilians with only $12 \%$ reporting unease at treatment compared with $20 \%$ globally (Fig. 2).

Patients were overall satisfied with the diagnosis consultation duration, and to a great extent seemed to understand the key topics of lifestyle changes, disease and its causes and drug treatment. Most of them seemed to accept the T2DM in a positive way.

Understanding of T2DM complications was slightly more limited, and there was a high level of disconnect between what physicians thought they had discussed and what patients were able to recall.

\section{Follow-up visits}

Follow-up visits occurred fairly regularly and lasted for $15 \mathrm{~min}$ on an average, with approximately 5 visits per year. Only a minority of people with diabetes stated they would like to see the physician more often. Interestingly, this was not associated with the actual frequency of visits. For example, the inter-visit length in Brazil for patients on diet and exercise treatment alone was approximately 12 weeks contrasting with 17.2 weeks globally; however, 1 in 4 Brazilian patients considered visits were very infrequent.

Patients on oral anti-hyperglycaemic agents or insulin had the same average frequency of visits. The follow-up visits were longer in Brazil (25 min) compared with the rest of the world $(13.4 \mathrm{~min})$. As expected, most of the consultation was spent on taking history and diagnosis tests to check if the disease was under control.

\section{Discussing complications}

Majority of physicians believed they had adequately explained T2DM complications to their patients, including approximately a third explaining the risk of potential early death. However, only a quarter of patients reported that they were worried about developing these

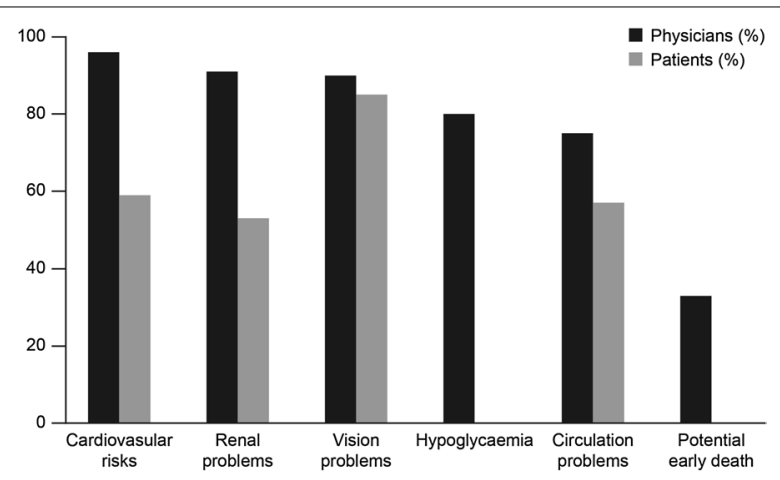

Fig. 2 Recollection of the risks and complications discussed during diagnosis consultation by physicians $(n=337)$ and patients $(n=206)$ complications of T2DM, while the rest were either not concerned or thought the risk was remote.

The complication that concerned patients the most was the potential of vision being affected or complications leading to blindness, with half of people reporting they were worried about this risk, while $21 \%$ reporting concern regarding cardiovascular disease. A higher proportion of Brazilian physicians recalled discussing the importance of complications, such as circulation problems ( $89 \%$ vs $71 \%$ ) and potential early death ( $44 \%$ vs $30 \%)$, to their patients. Paradoxically, fewer Brazilian physicians spent time explaining the potential impact of the disease on sexual health and fertility compared to the rest of the world ( $49 \%$ vs $65 \%)$.

Regarding patients' recall memory, more international patients recalled the discussion about potential kidney problems (59\% vs $39 \%$ ).

The risk of developing complications had a more profound effect on Brazilians; 39\% were devastated to hear they might develop complications versus $25 \%$ in the rest of the world.

Only 3\% of Brazilian patients were not concerned over the risk of developing complications compared with $10.8 \%$ globally, which was again proportionate to the increased time spent at the initial consultation. This concern also perpetuated into follow-up visits, where nearly $50 \%$ more Brazilians remained concerned through follow-up visits than in the rest of the world ( $72 \%$ vs $50 \%$ respectively). Despite this, apprehension over the need of future injectable therapy was a greater concern in Brazil than globally, both at diagnosis ( $59 \%$ vs $47 \%$ ) and at follow-up visits ( $51 \%$ vs $38 \%$ ).

Fewer Brazilian physicians believed their patients did not understand the serious consequences of hypoglycaemia and the importance of reporting events (58\% vs $67 \%$ ). Concordantly, Brazilian people with diabetes were less likely to know very little or nothing about hypos compared with the rest of the world ( $11 \%$ vs $21 \%)$. Further, Brazilians were more aware of the link between hypoglycaemia and premature mortality compared with other countries (13\% vs $4.4 \%)$.

\section{Treatment algorithm}

More than half of the physicians globally (53.2\%) agreed that early treatment using combination therapy could help control blood sugar levels and reduce risk of complications compared with only $25 \%$ in Brazil. Consequently, use of combination therapy as first line was very rare, with most physicians reserving this powerful approach for second line.

Despite acknowledgement that there were important differences in the needs of elderly patients or those with co-morbidities (as represented here by people with renal 
failure), initial treatment algorithms were remarkably similar, with only $7 \%$ physicians stating they would initiate combination therapy at diagnosis in patients diagnosed at 50 years, $9 \%$ for patients aged $>80$ and $7 \%$ for people with renal impairment. Interestingly, in this latter group, Brazilian physicians were more likely to recommend insulin at diagnosis compared with the rest of the world ( $34 \%$ vs $21.4 \%$, respectively).

Approximately a quarter of people with a new diagnosis of diabetes did not receive drug therapy at their initial consultation (25\% in Brazil and 23\% globally); however, nearly half of Brazilian physicians had initiated a drug within a month, compared with only a third in the rest of the world.

When questioned about their glycosylated haemoglobin (HbA1c), the majority of people with diabetes in all countries reported an $\mathrm{HbA} 1 \mathrm{c}$ between 6.5 and 7.5\%; however, a third of participants in Spain and Brazil did not know their HbA1c levels (Table 3).

When questioned about the willingness to comply with lifestyle advice, approximately half of patients reported no intention of changing their diet, and three-fifth did not intend to exercise more. Reasons for this willful non-compliance were very similar globally. Interestingly, proportion of those reporting financial concerns as a justification for the lack of compliance was almost identical in Brazil compared with the rest of the world (19 and $18 \%)$.

\section{Potential for improvement}

Over half of physicians in Brazil and the rest of the world reported the desire for more time to discuss disease management to achieve better adherence to therapies, lifestyle changes, obesity management and early screening (Brazil 55 and $56 \%$ globally).

Better treatment options was second on physicians' wish list. This was particularly pertinent amongst Brazilian physicians who desired more effective treatments, easier drug regimen, less frequent administration and medications with fewer side effects/lower risk of hypos ( $40 \%$ vs $24 \%$ ). Inconsistently, Brazilian physicians were half as likely to request more patient education programs compared to international physicians ( $7 \%$ vs $17 \%$ ).

\section{Discussion}

The Time to do More in diabetes survey demonstrated a clear disconnect in communication between healthcare providers and people with diabetes [10]. We have demonstrated that by allowing more time for patients in Brazil and having a greater involvement of specialists at an early stage, people with T2DM in Brazil have a good understanding of the risk of hypoglycaemia and increased awareness of the risks of poorly controlled diabetes compared with the rest of the world. Notwithstanding engagement in the basic interventions such as diet and lifestyle remained low, albeit better in the Brazilian population than in the rest of the world.

In 2013, a National Health Survey in Brazil, showed that $6.9 \%$ of the population aged $\geq 18$ years self-reported diabetes mellitus. There was a higher rate of diagnosis of diabetes (9.6\%) among individuals with no education or with incomplete elementary school. Rates ranged from $0.6 \%$ (age group 18-29 years) to 19.9\% (age group 65-74 years). There was no statistically significant difference in the diagnosis rates among whites, blacks and mixed race individuals [11].

At diagnosis, a quarter of consultations lasted over 41 min, substantially more than that noted globally; however, this did not necessarily translate to increased patient satisfaction, with half of Brazilian patients believing that they did not have time to explain their fears and concerns. Diet and exercise were discussed at length by the physicians, but only two-thirds of the patients understood the importance of these lifestyle interventions.

The current Brazilian guidelines, in an attempt to combat clinical inertia, acknowledge that monotherapy is

Table 3 Average blood sugar levels (HbA1c) reported by the patients during survey

\begin{tabular}{|c|c|c|c|c|c|c|c|}
\hline $\begin{array}{l}\text { Average blood sugar/ } \\
\text { HbA1c levels }\end{array}$ & $\begin{array}{l}\text { USA } \\
(n=151)\end{array}$ & $\begin{array}{l}\text { UK } \\
(n=100)\end{array}$ & $\begin{array}{l}\text { India } \\
(n=100)\end{array}$ & $\begin{array}{l}\text { Japan } \\
(\mathrm{n}=101)\end{array}$ & $\begin{array}{l}\text { Spain } \\
(n=100)\end{array}$ & $\begin{array}{l}\text { All five countries } \\
(n=552)\end{array}$ & $\begin{array}{l}\text { Brazil } \\
(n=100)\end{array}$ \\
\hline$\leq 6.5 \%$ & 28 & 20 & 14 & 39 & 18 & 24 & 5 \\
\hline$>6.5$ and $\leq 7.0 \%$ & 21 & 18 & 31 & 23 & 12 & 21 & 25 \\
\hline$>7.0$ and $\leq 7.5 \%$ & 16 & 18 & 25 & 15 & 17 & 18 & 23 \\
\hline$>7.5$ and $\leq 8.0 \%$ & 5 & 10 & 9 & 7 & 10 & 8 & 6 \\
\hline$>8.0$ and $\leq 8.5 \%$ & 3 & 3 & - & 5 & 2 & 3 & 4 \\
\hline$>8.5 \%$ & 1 & 5 & 2 & 3 & 6 & 3 & 4 \\
\hline I don't know & 26 & 26 & 19 & 9 & 35 & 23 & 33 \\
\hline
\end{tabular}

Values are represented as percentages

HbA1c glycosylated haemoglobin 
unlikely to achieve glycaemic control if $\mathrm{HbA1c}$ at diagnosis is $>7.5 \%$ or fasting glucose is $>200 \mathrm{mg} / \mathrm{dL}$ [12]. Therefore, the guidelines recommend combination therapy at diagnosis in patients with high baseline HbA1c. The use of combination therapy at diagnosis could positively influence the durability of glycaemic control, changes in insulin sensitivity and $\beta$-cell function, time to insulin introduction, influences diabetic complications and the effects on some surrogates [13].

Three of the most important medical societies in Brazil (diabetes, endocrinology and cardiology) have teamed up to set a multidisciplinary management diabetes guideline. One important statement was that fighting clinical inertia, defined as delay in treatment schedule at the appropriate time, should be effective for glycaemic targets, blood pressure and lipid (unpublished data). However, in our survey, only $25 \%$ of Brazilian physicians indicated they would initiate combination therapy at outset. This figure was similar to that reported globally, suggesting there is a global inertia to commencing combination therapy, while the physicians acknowledged the scientific evidence behind the introduction of early combination.

This is an interesting paradox of diabetes management-a cardiologist would not hesitate to add multiple anti-platelet agents, anti-hypertensives and statin therapy at the diagnosis of myocardial infarction; a respiratory physician would routinely initiate combination of longacting $\beta-2$ agonist and steroid therapy if the patient was sufficiently compromised, yet despite established evidence that a single oral agent is very unlikely to achieve good glycaemic control and address the key pathophysiological features of diabetes, most diabetologists will nevertheless implement a sub-optimal "treat-to-fail" strategy. Substantial training and re-education will be required in order to achieve adoption of current national and international guidelines to implement combination therapy at diagnosis.

Brazilian physicians do escalate care quickly than the rest of the world, with one-third more Brazilian patients receiving treatment shortly after diagnosis. This might reflect an acknowledgement of Brazilian Diabetes Society's guidelines, suggesting rapid escalation of treatment until fasting glucose $<100 \mathrm{mg} / \mathrm{dL}$, pre-prandial glycaemia $<130 \mathrm{mg} / \mathrm{dL}$, postprandial glycaemia $\leq 160 \mathrm{mg} / \mathrm{dL}$, and $\mathrm{HbA} 1 \mathrm{c}<7 \%$ to avoid clinical inertia [12].

Importantly, there is a significant disconnect between what physicians say they have discussed with patients and what patients actually remember. Physicians wish to discuss issues of scientific importance; however, this often does not answer patients' beliefs, fears and apprehensions.

Therefore, an important conclusion of this survey is that physicians should spend a long time determining the concerns, uncertainties and hesitations of people with diabetes before trying to impart their concern for their patients upon them.

The increased time spent at diagnosis consultation among the Brazilian patients, however resulted in a greater awareness of the risk of cardiovascular disease from the sum of multiple risk factors, and addressing these risk factors is very important for the prevention of up to two-third of deaths among people with diabetes [14].

At the time of the diagnosis, most of the people with diabetes were scared and insecure. Consequently, it is important to completely reassure the patients that with good glycaemic, lipid and blood pressure control, a normal quality of life and longevity can be achieved. Determining strategies to achieve good glycaemic control, including lifestyle changes, physical activity, healthy nutrition, self-monitoring, medical treatment compliance, consultation regularity and family involvement should become a priority.

Another advantage of the longer time with the physician at diagnosis was a greater, albeit low understanding of the importance of lifestyle changes. Brazilians recall $6 \%$ of the diagnosis consultation time spent discussing risks and complications of T2DM, compared with $9 \%$ globally.

The difference between the complications of greatest concern between the physicians and people with diabetes is interesting. Physicians were predominantly interested in complications with the highest mortality, with cardiovascular disease being of greatest concern. In contrast, people with diabetes, were far more interested in complications with an impact on the quality of life, notably retinopathy and nephropathy which is of major importance in clinical practice.

These microvascular complications, of greatest concern to our patients, have been demonstrated to be reduced by lifestyle changes including diet and exercise [15] and good metabolic control $[16,17]$. If physicians focused on these quality of life-based discussions of complications rather than mortality-based discussions it addresses the greatest concern of patients, thereby improving engagement. Further, emphasis on treatable complications may invoke better commitment to diet, exercise and pharmacological therapy regimens.

This commitment may reap rewards in other areas, notably the risk of ulcer, amputation and severe neuropathy, in the diabetic foot. A recent multicentre study of 1455 people with diabetes in Brazil suggested a higher proportion of patients with neuropathic disease, predominantly neuroischaemic in nature, and a smaller number of patients with isolated ischaemic disease [18], compared to similar studies performed in the USA [19] and Western Europe [20]. 
Likewise, the prevalence of erectile dysfunction is higher among Brazilians than Western Europeans, with up to $74.6 \%$ of men with T2DM being affected, as assessed by international index of erectile function (IIEF-5) score [21]. In our study, the potential impact of diabetes on sexual health and fertility was given substantially less time in Brazil, with only $49 \%$ of physicians including it in their overview of potential complications compared to $64.6 \%$ in the other countries surveyed. At best, this indicates that patients may not completely be aware of the risks and potential treatments, and at worst, this lack of understanding could be contributing to the high-risk prevalence in Brazilian men and reduced quality of life.

\section{Study limitations}

Although every effort was made to ensure the generalisability of the populations sampled, by utilising an online survey with predefined quotas, we may have generated some selection bias towards participants who are more technologically aware, more so in the people with diabetes than the physicians. However, we are more likely to have over-recruited the motivated and more educated, thus suggesting the true dissociation between physician and people with diabetes may be greater than represented here.

The use of the online questionnaire, however, is justified because it, for the first time, allowed survey of a large number of people with diabetes across six countries, specifically chosen to represent the different health care structures, from the entirely free at the point of delivery NHS service in the UK to the entirely private sector in the USA.

\section{Conclusions}

Clinical inertia represents a considerable barrier to optimal diabetes treatment. A greater understanding of specific impediments to escalating care, particularly from the interactions between physicians and people with diabetes in Brazil, may help identify and therefore address the unmet needs of the population. Brazil offers more time than many other countries around the world to its newly diagnosed people with diabetes. However, we have highlighted that our principle concerns as health care providers, notably on preventing major cardiovascular events, are not the same as the priorities of our patients, who are more concerned about the microvascular complications that will impact quality rather than quantity of life. Adapting our consultation strategies to incorporate these patient-focused topics may improve understanding of the condition and ultimately engagement in self-management of the disease.

\section{Abbreviations}

BMI: body mass index; GP: general practitioner; HbA1c: glycosylated haemoglobin; IIEP: international index of erectile function; NHS: National Health Service; PCPs: primary care physicians; T2DM: type 2 diabetes mellitus.

\section{Authors' contributions}

SV, PMP, MB, and WDS contributed to the design of the survey and the initial data interpretation. SV, DG and RCV drafted the first draft of the Brazilian sub analysis. All the authors participated in data interpretation, manuscript revisions and approved the final manuscript for submission. The authors thank Ishita Guha Thakurta (Novartis Healthcare Private Limited, Hyderabad, India) for editorial assistance. All authors read and approved the final manuscript.

\section{Author details}

${ }^{1}$ Federal University of Goiás-Postgraduate Programme, Goiânia, Brazil.

${ }^{2}$ Novartis Pharma AG, Basel, Switzerland. ${ }^{3}$ Department of Medicine, University of Leipzig, Leipzig, Germany. ${ }^{4}$ Uninove University, São Paulo, Brazil. ${ }^{5}$ Catholic University of Goiás, Goiânia, Brazil. ${ }^{6}$ Diabetes and Vascular Medicine, University of Exeter Medical School, Exeter, UK. ${ }^{7}$ Avenida T-4 número 313 Setor Bueno, Goiânia, Goiás CEP 74884-582, Brazil.

\section{Acknowledgements}

The authors express their sincere gratitude to all the participants of the survey.

\section{Competing interests}

SV reports grants and personal fees from Boehringer-Ingelheim, Novartis, and Novo Nordisk. PMP is employed by and own shares in Novartis. MB reports grants and personal fees from Bayer, Boehringer-Ingelheim, Novartis, Novo Nordisk; grants from Riemser; personal fees from Sanofi Aventis, Lilly, BristolMyers Squibb, Roche, AstraZeneca, MSD, Daiichi-Sankyo, Ipsen, Johnson \& Johnson, Pfizer, Takeda. WDS reports personal fees from Novartis, BoehringerIngelheim, Pfizer, grants and personal fees from Novo-Nordisk. DG and RCV declare that they have no competing interest.

\section{Availability of data and materials}

The corresponding author can be contacted for any information related to this paper.

\section{Consent for publication}

All other authors have read the manuscript and have agreed to submit it in its current form for consideration for publication in the journal.

\section{Ethics approval and consent to participate}

Individuals from six countries (Brazil, India, Japan, Spain, UK, USA) were randomly selected from the Kantar Health panel of over 2500 physicians and 118,000 patients who have agreed to be contacted for research purposes.

\section{Funding}

The online survey was supported by Novartis.

\section{Publisher's Note}

Springer Nature remains neutral with regard to jurisdictional claims in published maps and institutional affiliations.

Received: 18 November 2016 Accepted: 8 June 2017

Published online: 15 June 2017

\section{References}

1. International Diabetes Federation. IDF diabetes atlas. 7th ed. Brussels: International Diabetes Federation; 2015. http://www.diabetesatlas.org. Accessed 3 Nov 2016.

2. Stratton IM, Adler Al, Neil HA, Matthews DR, Manley SE, Cull CA, Hadden D, Turner RC, Holman RR. Association of glycaemia with macrovascular and microvascular complications of type 2 diabetes (UKPDS 35): prospective observational study. BMJ. 2000;321:405-12. 
3. Del Prato $S$. Megatrials in type 2 diabetes. From excitement to frustration? Diabetologia. 2009;52:1219-26.

4. Strain WD, Blüher M, Paldánius P. Clinical inertia in individualising care for diabetes: is there time to do more in type 2 diabetes? Diabetes Ther 2014:5:347-54.

5. Casagrande S, Fradkin J, Saydah S, Rust K, Cowie C. The prevalence of meeting A1C, blood pressure, and LDL goals among people with diabetes, 1988-2010. Diabetes Care. 2013;36:2271-9.

6. Paul SK, Klein K, Thorsted BL, Wolden ML, Khunti K. Delay in treatment intensification increases the risks of cardiovascular events in patients with type 2 diabetes. Cardiovasc Diabetol. 2015:14:100.

7. Huang LY, Shau WY, Yeh HL, Chen TT, Hsieh JY, Su S, Lai MS. A model measuring therapeutic inertia and the associated factors among diabetes patients: a nationwide population-based study in Taiwan. J Clin Pharmacol. 2015;55:17-24.

8. Khunti S, Davies MJ, Khunti K. Clinical inertia in the management of type 2 diabetes mellitus: a focused literature review. Br J Diabetes Vasc Dis. 2015;15:65-9.

9. Zafar A, Stone MA, Davies MJ, Khunti K. Acknowledging and allocating responsibility for clinical inertia in the management of Type 2 diabetes in primary care: a qualitative study. Diabet Med. 2015;32:407-13.

10. Strain WD, Cos X, Hirst M, Vencio S, Mohan V, Vokó Z, Yabe D, Blüher M, Paldánius PM. Time to do more: addressing clinical inertia in the management of type 2 diabetes mellitus. Diabetes Res Clin Pract. 2014;105:302-12.

11. de Almeida-Pititto B, Dias ML, de Moraes AC, Ferreira SR, Franco DR, Eliaschewitz FG. Type 2 diabetes in Brazil: epidemiology and management. Diabetes Metab Syndr Obes. 2015;8:17-28.

12. Lerario AC, Chacra AR, Pimazoni-Netto A, Malerbi D, Gross JL, Oliveira JE, Gomes MB, Santos RD, Fonseca RM, Betti R, Raduan R. Algorithm for the treatment of type 2 diabetes: a position statement of Brazilian Diabetes Society. Diabetol Metab Syndr. 2010;2:35.

13. Del Prato S, Foley JE, Kothny W, Kozlovski P, Stumvoll M, Paldánius PM, Matthews DR. Study to determine the durability of glycaemic control with early treatment with a vildagliptin-metformin combination regimen vs. standard-of-care metformin monotherapy - the VERIFY trial: a randomized double-blind trial. Diabet Med. 2014;31:1178-84.

14. ACCORD Study Group. Effects of intensive glucose lowering in type 2 diabetes. N Engl J Med. 2008;358:2545-59.

15. Look AHEAD Research Group. Cardiovascular effects of intensive lifestyle intervention in type 2 diabetes. N Engl J Med. 2013;369:145-54.

16. ADVANCE Collaborative Group. Intensive blood glucose control and vascular outcomes in patients with type 2 diabetes. N Engl I Med. 2008;358:2560-72.

17. UKPDS Group. Intensive blood-glucose control with sulphonylureas or insulin compared with conventional treatment and risk of complications in patients with type 2 diabetes (UKPDS 33). UK Prospective Diabetes Study (UKPDS) Group. Lancet. 1998;352:837-53.

18. Parisi MC, Neto MA, Menezes FH, Gomes MB, Teixeira RM, de Oliveira JE, Pereira JR, Fonseca RM, Guedes LB, E Forti CA, de Oliveira AM, de Nóbrega MMB, Colares VN, Schmid H, Nienov OH, Nery M, Fernandes TD, Pedrosa HC, Schreiber de Oliveira Cda S, Ronsoni M, Rezende KF, Quilici MT, Vieira AE, de Macedo GM, Stuchi-Perez EG, Dinhane KG, Pace AE, de Freitas MC, Calsolari MR, Saad MJ. Baseline characteristics and risk factors for ulcer, amputation and severe neuropathy in diabetic foot at risk: the BRAZUPA study. Diabetol Metab Syndr. 2016;8:25.

19. Boyko EJ, Ahroni JH, Cohen V, Nelson KM, Heagerty PJ. Prediction of diabetic foot ulcer occurrence using commonly available clinical information: the Seattle Diabetic Foot Study. Diabetes Care. 2006;6:1202-7.

20. Prompers L, Huijberts M, Alpeqvist J, Jude E, Piaggesi A, Bakker K, Edmonds M, Holstein P, Jirkovska A, Mauricio D, Tennvall GR, Reike H, Spraul M, Uccioli L, Urbancic V, Van Acker K, Van Baal J, Van Merode F, Schaper N. Delivery of care to diabetic patients with foot ulcers in daily practice: results of the Eurodiale study, a prospective cohort study. Diabet Med. 2008;25:700-7.

21. Severo MD, Leiria LF, Ledur Pdos S, Becker AD, Aguiar FM, Massierer D, Gus M, Schaan BD. Association between erectile dysfunction and echocardiographic variables of ventricular hypertrophy and diastolic function in hypertensive patients with type 2 diabetes mellitus: a cross-sectional study. J Diabetes. 2014;6:586-9.

\section{Submit your next manuscript to BioMed Central and we will help you at every step:}

- We accept pre-submission inquiries

- Our selector tool helps you to find the most relevant journal

- We provide round the clock customer support

- Convenient online submission

- Thorough peer review

- Inclusion in PubMed and all major indexing services

- Maximum visibility for your research

Submit your manuscript at www.biomedcentral.com/submit
( ) Biomed Central 